\title{
Child Abuse Investigation: Police Officers and Secondary Traumatic Stress
}

\author{
Alison D. MacEachern \\ Divya Jindal-Snape \\ Sharon Jackson
}

School of Education, Social Work and Community Education, University of Dundee, Dundee, UK

Child protection is an area of police work which has expanded in the last decade, leading to an increase in the number of police officers working in departments which specialise in investigating cases of child abuse. Police officers in this field may be at greater risk of experiencing secondary traumatic stress but there remains a paucity of research in this area of policing. Analogies can be drawn to existing research in policing and with social service workers involved in child protection. The paper finishes off with implications for police forces to ensure safe working environments and appropriate counselling for employees.

$$
\text { child protection secondary traumatic stress police }
$$

\section{INTRODUCTION}

It has long been acknowledged that police personnel have to respond to a variety of situations which may be considered shocking, disturbing and upsetting to many people. An area of policing increasingly characterised as traumatic for police personnel and which exposes employees to negative stress is the investigation of child abuse/ child protection cases [1]. Although an area of policing which has seen rapid expansion in the last two decades, the effects of such work on the officers conducting the enquiries remains an area rarely the focus of research. Early indications on conducting an international and national review of available literature, revealed a paucity of work in relation to the discipline of police officers who investigate child protection cases and the effects of secondary traumatic stress (STS), as such reference is made to studies of social service work to draw an analogy.

This paper looks at the available literature on STS and the impact on public service personnel, specifically police personnel with responsibility for investigating child protection.

\section{DEFINING TRAUMA AND TRAUMATIC EVENTS}

Duckworth refers to psychological trauma as the "severe emotional and mental disruption which can follow the experience of certain kinds of extreme events-including those where there is no physical injury" (p. 35) [2]. In comparison, Cardwell refers to trauma as "a psychological injury caused by an emotional event” (p. 255) [3], whereas the Collins Paperback English Dictionary defines trauma as "an emotional shock that may have long lasting effects" (p. 923) [4].

For the purposes of this paper the description of traumatic incidents conceptualised by Mitchell and Resnick will be used, i.e., "any situation faced by emergency personnel that causes them to experience strong emotional reactions which have a potential to interfere with their ability to function

This paper is based on a literature review undertaken by the first author, as part of her doctoral work, MacEachern AD. An exploration into the experiences of police officers who investigate child protection cases and secondary traumatic stress [doctoral dissertation]. Dundee, UK: University of Dundee; 2011.

Correspondence and requests for offprints should be sent to Divya Jindal-Snape, School of Education, Social Work and Community Education, University of Dundee, Dundee, Nethergate, Dundee DD1 4HN, UK. E-mail: <d.jindalsnape@dundee.ac.uk>. 
either at the scene or later" (p. 3) [5]. The psychological consequences of experiencing such traumatic events have been widely written about in published texts, journal articles and more increasingly in the new millennium explicitly documented in the daily tabloids, providing an insight into the nature and dynamics of traumatic stress [6].

\section{STS}

Figley asserts STS to be a natural behaviour or emotion caused by knowing about a traumatising event which has happened to a family member; he considers that this form of stress is a result of "helping or wanting to help a traumatised or suffering person" (p. 10) [7].

\subsection{Prevalence of STS in Service Professionals}

One cannot be confident that complete and accurate figures of people suffering from the prevalence of secondary trauma are available as it is only since 1990s that researchers have started focussing on secondary trauma. In the USA, studies on the prevalence of exposure to traumatic events have found it to range from 40 to $81 \%$ of the general population $[8,9,10]$.
Since the 1990s, the number of published studies on STS experienced by service providers has been increasing [11]. Studies conducted in the 1990s mainly focussed on the professional providers of psychosocial services. More recently Bride, Jones and MacMaster focused on STS in child protection service workers and amongst social workers [12]. Helm asserts that practitioners may experience many symptoms including feelings of being overwhelmed, anxious, emotional numbness, and inability to experience pleasure, while suffering despair, resentment and emotional exhaustion. Helm further asserts that practitioners can also experience self-loathing, intrusive thoughts, moments of deep rage, crying, intolerance, cynicism in their outlook on life and nightmares (p. 4-5) [13]. Research has suggested that such feelings are psychological responses of identification with victims (Figure 1).

According to Herman, psychosocial service providers supporting and providing therapy to traumatised individuals, often share the emotional burden of the trauma, bearing witness to damaging or cruel circumstances that individuals have experienced and have to acknowledge the existence of terrible and traumatic events in the world [14]. McCann and Pearlman [15] and Figley $[16,17]$ affirm that effective interventions with survivors of trauma involves assisting individuals to work through the traumatic events

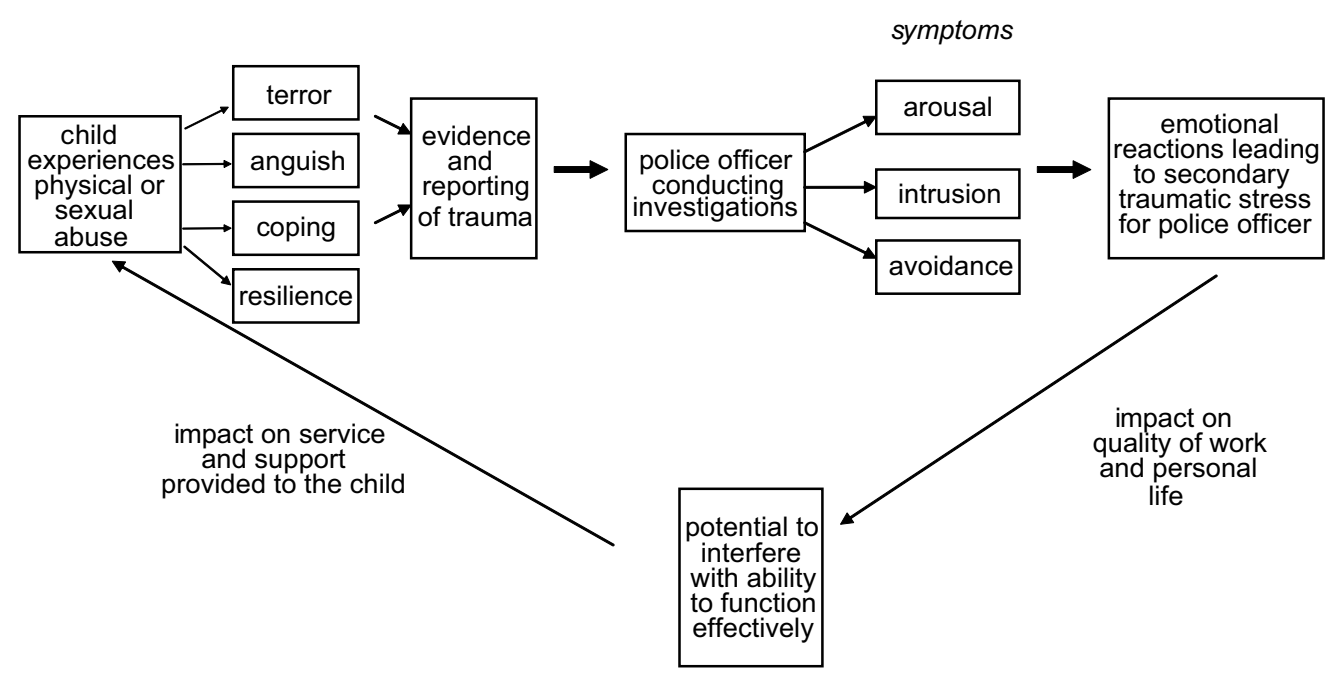

Figure 1. Generation of secondary traumatic stress and impact on practice. 
and experiences, involving the survivor recounting the circumstances of the event with the service professional to bring about closure. McCann and Pearlman further assert that as a direct consequence of the process, service providers are repeatedly encountering traumatic events through vivid and detailed descriptions of what the survivor has directly experienced, which may result in the emergence of STS symptoms similar to the indicators of post traumatic stress disorder (PTSD).

Although literature on STS has recently mushroomed, the limitations of studies should not be overlooked. Kassam-Adams asserted that a large percentage of the literature was theoretical, hypothetical or anecdotal [18]. Kassam-Adams further argued that empirical studies on STS amongst service professional were limited in the extent to which the existing measures used were receptive enough to detect "differences amongst service professional experiencing secondary exposure" (p. 36) [18]. In the USA and the UK, the two major organisations responsible for child protection enquiries and investigations are the police and social work services. However, it has only been in recent years that research has expanded to include child welfare workers and the effects of STS [19].

\subsection{Police Personnel and STS}

Police officers have been shown to have a highly stressful and demanding occupation [20, 21, 22]. Most literature on police officers focusses on the psychological effects of police work and the stresses connected with the job. A growing number of publications has focussed on the negative aspects of policing, namely traumatic stressors [23], organisational stressors [24] and individual factors, i.e., personality and coping [25] arguing that all or any of those variables can have an impact on police officers and their experience of secondary trauma.

Due to the diverse nature of policing, compiling a comprehensive and absolute list of police job stressors that can be universally referred to by researchers around the world is unrealistic and, as a result, there is no collective definition of a traumatic incident. Numerous researchers studying the exposure of police officers to traumatic incidents, PTSD, STS and vicarious trauma have used different traumatic incidents and developed scales and surveys for this purpose. Speilberger, Westbery, Grier, et al. developed a 60-item survey in which they listed 60 incidents considered traumatic by police officers [26]. Other studies conducted by Sewell [27] and Coman and Evans [28] have concentrated on firearms incidents and their impact on officers. According to Violanti and Aron, police officers rank situations such as battered children, high speed car chases, the use of force and aggressive crowds as amongst the most stressful situations attended [23].

In a study of 233 police officers in the USA, Patterson chose six items/areas of policing (five from Speilberger et al. [26] and one from Coman and Evans [28]) [29]. The study found that the most frequently occurring traumatic incidents for police officers in the sample were occasions in which family members and children were involved, followed by situations in which officers or others were at risk of being seriously injured or killed in primarily nonfamilial-related situations.

Mitchell, Stevenson and Poole studied the perceptions regarding a memorable critical incident of 612 police officers from Strathclyde Police (response rate of 49.1\%), 768 Royal Ulster Constabulary (response rate of $46.5 \%$ ) and 41 chief constables from the 55 constabularies in the UK (response rate of 73\%) [30]. Incidents included murders, suicides and accidental deaths, road traffic deaths, Lockerbie disaster (bombing of Pan Am flight 103, December 21, 1988), the RAF Chinook helicopter disaster (Chinook helicopter ZD516, crashed on the Mull of Kintyre, killing all 29 people on board), threatening and dangerous situations, abuse and cruelty. When considered with Violanti and Aron's findings, it could be argued that child protection and domestic incidents are two occurrences that police officers consider the most stressful and traumatic [23]. However, the limitations of both studies should not be overlooked (such as the sample of respondents, their location and number), nor should the 
findings be taken as wholly representative of all police officers around the world. This provides a strong rationale for undertaking longitudinal research on a national and international basis.

The issue of police officers and their exposure to trauma and their experience of secondary trauma is further complicated, as not all police officers will be affected in the same manner following exposure to traumatic incidents. Stratton, Parker and Snibble on conducting research on police officers and their exposure to traumatic incidents found that $35 \%$ of the officers in their sample involved in a firearms (shooting) incident, described not being affected at all either psychologically or physically, while $33 \%$ of officers described moderate effects and $30 \%$ reported being very affected by the incident [31]. According to Violanti many police officers experience symptoms of PTSD [32].

Stephens, Long and Miller's study of 527 working police officers conducted in New Zealand found that the number of traumatic events was positively correlated with the intensity of PTSD symptoms and that repeated experiences of the same type of event predicted higher PTSD scores [33]. Moran and Britton asserted that police officers accumulating incidents attended over the years of service, experienced a "stair step" phenomenon in which unresolved previous trauma builds on itself [34]. So, researchers should not overlook the personal history of professionals, including police officers [35].

Buchanan, Stephens and Long investigated the traumatic event experiences of 187 police recruits (probationers) and 177 serving (confirmed in the rank) officers, both groups consisted of male and female officers [36]. Using the Traumatic Stress Schedule Norris recorded the frequency of trauma experienced prior to and since joining the police in relation to 10 categories [37]. The categories included incidences of robbery, assault, sexual assault, tragic deaths, fires, disasters, hazards, vehicle crashes/motor accidents, military combat and other events. Experienced officers reported more lifetime events and significantly more lifetime exposure to assaults, disasters, hazards and motor vehicle accidents; male recruits reported significantly more lifetime assaults than females. Females reported high lifetime levels of sexual assaults. Both male and female recruits recorded similar lifetime levels of other events. According to Buchanan et al., the number of traumatic events experienced as young adults is an important variable in determining vulnerability to developing psychological symptoms if exposed to future trauma [36]. Bonifacio asserted that police officers, although aware of the dangers associated with police work, took the job to contribute something worthwhile to society [20]. It could be argued that one such area where police officers may be repeatedly exposed to traumatic incidents is the field of child protection, where officers' core business is that of investigating cases of child abuse.

Martin, McKean and Veltkamp looked at the impact of working with survivors of sexual assault on police officers and found that PTSD symptoms were significantly more prevalent amongst police officers dealing with rape survivors than those police officers who dealt with routine crimes and offences [38]. Follette, Polusny and Milbeck on examining the impact of providing services to sexual abuse survivors also found that such work was significant to police officers [39].

Wright, Powell and Ridge explored police officers' perceptions of the daily challenges involved in child abuse investigations across three Australian states [40]. The study examined how officers considered such enquires to affect their ability to undertake their role and the management of the challenges they faced. The study employed a qualitative methodology, consisting of indepth interviews of a diverse sample of 25 police officers working in child abuse units. The study found heavy caseloads and collaboration with other professional groups to be the two key sources of negative work stress frequently associated with child abuse investigations. According to Wright et al., despite the provision of organisational strategies aimed at reducing work stressors, police officers tended to rely predominately on informal coping mechanisms such as peer support and humour [40]. 


\section{POTENTIAL IMPACT ON PRACTICE}

Reviewing the literature on professional groups employed in fields that support, treat and investigate survivors of trauma and victims of crime has shown that such professionals are at a heightened risk of suffering STS, as a result of their vocation. It is recognised, however, that not all employees who are exposed to such pressures in their work develop negative trauma symptomlogy [41]. For personnel who develop trauma symptomlogy, there are potential implications for practice, and ultimately for the service users (see Figure 1). The implications of stress and secondary trauma for organisations has been brought into sharp focus in recent years by a number of high profile legal rulings and an increasing recognition that employers are responsible for the psychological, as well as the physical welfare of their employees. According to Bride, professionals experiencing STS may be one reason why many service professionals, including social workers, leave their profession early or opt for less stressful positions within organisations [42].

In Alexander, Walker, Innes, et al.'s study, 100 police officers from Grampian Police were surveyed in relation to police stress at work (response rate of 76\%) [43]. The survey found that negative effects of stress fell into the following areas: increased sickness and absence from duty, poor work performance, job dissatisfaction, reduction in motivation, the impairment of ability to perform complex tasks, maladaptive coping mechanisms such as over indulgence in alcohol, and raised levels of aggression and irritability. Alexander et al. asserted that any one or all of the above could have an impact on police officers' efficiency and effectiveness [43]. When police officers respond to stress and trauma with raised levels of irritability and aggression when dealing with the public, they may become an immediate danger to the reputation of the organisation and, more importantly, provide a reduced service to the public which they serve, leading to members of the public being traumatised by their experiences of the police and additional damage being caused [43].

Griggs (2005, as cited in Gallo [44]) argued that "elevated stress creates a deadly continuum that begins by undermining our emotional stability and paves the way the way to a variety of inappropriate copying mechanisms". She further asserted that educating police personnel how to cope with job stressors was "as important as using their personal protective equipment"

The Health and Safety Executive on conducting numerous studies on the effects of stress in the work place estimated that "nearly half a million people (442000) in Britain report work related stress at a level they believe is making them ill" [45]. In 1995/96, the Health and Safety Executive calculated stress related problems to cost the public and organisations at least $£ 3.7$ billion each year [46]. In recent times, there has been an increase in litigation relating to negligently inflicted psychiatric damage, around the globe [47]. In Australia, a police officer was awarded $\$ 750000$ in compensation for mental injury after being diagnosed as suffering from PTSD following investigations into crimes against children [40]. Similarly the Police Federation of Northern Ireland brought a class action lawsuit for police officers from the Royal Ulster Constabulary, to compensate the officers who suffered from PTSD. According to Gilligan, exposure to traumatic incidents was not the basis on which a class action could be taken, police federation press release pointed out that police officers knew and accepted the risks of working as police officers in Northern Ireland but were not adequately equipped to deal with the psychiatric and psychological consequences of some incidents [48, 49]. Consequently, it was suggested that the Royal Ulster Constabulary should conduct systematic risk assessments which would assist its employees to deal with the psychological hazards involved in fighting a counterinsurgency war.

In England, police attending operationally challenging incidents such as Hillsborough and the Bradford Fire resulted in officers and survivors claiming for damages due to traumatic injury. In Scotland, operationally challenging 
incidents such as Lockerbie, Dunblane Primary School Massacre (murder of 16 children and their teacher) and the Mull of Kintyre Chinook Helicopter crash did not result in police personnel claiming damages as a result of their attendance and investigations of such incidents. Many police departments throughout the world have recognised the negative consequences associated with work-related stress, with organisation administrators developing strategies, procedures and policies to help assist officers and their families. Organisations can help reduce the negative consequences of officers' stress and trauma for not only the benefit of the officers and their families but also the communities which the police serve [50].

This is further emphasised by McFarlane and Bryant's review of literature; they argued that in high risk occupations, where the possibility of PTSD is high, employers should be ready to provide support to their employees. This includes managing the risk by early recognition of symptoms, establishment of screening and monitoring of employees who are at high risk, and prompt treatment. They believe that this anticipation will provide opportunities to provide early treatment and avoid any ensuing problems that can be debilitating for the employee [51].

Linked with the UK legal system failing to acknowledge the existence of STS and the effects on police officers, there has been little impetus in the past for forces to acknowledge the effect of STS on its employees, specifically those tasked with investigating child abuse/child protection cases. With an increasing acknowledgement of the existence of STS in the field of traumatology and its effects on the professionals who work with traumatised individuals, including social service workers and police officers, police forces and the legal bodies charged with protecting chief constables' interests and vicarious liability, will need to ensure that clear policies outlining preventative strategies are in place to minimise the risks of STS.

Given the legal obligation of organisations (including police forces) to ensure safe working environments under the Health and Safety Act 1974 and Health and Safety at Work Regulations
1999, it is increasingly recognised that employers are responsible for the psychological and physical well-being of their employees. Force standard operating procedures affirm that it is a responsibility of all managers and supervisors to demonstrate their commitment to health and safety through their actions in support of force policy. Since the late 1990s, most police organisations throughout the UK have used a variety of post-incident debriefing and critical incident stress management methods, in addition to formally recognising that the police service must demonstrate a duty-of-care to police officers and force support staff.

In this regard most UK police have in place critical incident management and support services to assist staff cope with stress; occupational health departments offer critical incident stress debriefing and employee well-being programmes.

The Association of Chief Police Officers in Scotland (ACPOS) is determined that the Scottish Police Service is "committed to providing support to staff exposed to critical incidents" further recommending that forces use a system of critical incident management designed to provide a "supportive framework for staff who have attended, or been involved in the management of a critical incident" (p. 1) [52]. The intention of the critical incident stress management (CISM) policy is to diminish the adverse psychological influence of stressful work-related incidents. Many British forces have entrenched in their CISM processes critical incident stress debriefing (CISD).

\section{CISD}

Psychological debriefing or CISD was developed in the early 1980s to prevent the development of post-traumatic stress amongst emergency services professionals and those involved in other high risk disciplines [53]. Not only have the emergency services adopted CISD but in recent years such psychological debriefing has become increasingly popular amongst companies involved in banking, supermarket chains and retailing following disasters or distressing incidents. Police work may occasionally involve 
some police officers and force support officers exposed to operationally challenging incidents that may have the potential to adversely affect their physical and emotional well-being. Since the late 1990s, most police organisations throughout the UK have used a variety of postincident debriefing and CISM methods, in addition to formally recognising that the police service must demonstrate a duty of care to police officers and force support staff. Mitchell et al. surveyed all 55 UK police forces/constabularies with a postal questionnaire to ascertain details about the various practices in relation to CISD/post-incident care [30]. Fifty-five questionnaires were distributed, 41 were returned (response rate: $71 \%$ ). Most forces had clearly delineated definitions of what they considered to be a critical incident for the purposes of stress management. Definitions included situations faced by individuals that cause unusual strong reactions which interfere with their life or work, death or serious injury involving people and particularly children.

Most police organisations have such definitions of critical incidents now entrenched in their policy statements and standard operating procedures. ACPOS define a critical incident as "an incident in which the experiences of being involved may surpass the perceived normal coping mechanisms of those involved whether directly or indirectly" (p. 1) [52].

In 1994, a large Scottish force in conjunction with a Scottish university initiated a critical incident debriefing programme under the auspices of the then Occupational Health and Welfare Unit (Occupation Health). The programme established mechanisms to address situations in which police officers and force support officers may have been affected. In a bid to lessen the impact of such incidents on staff, most Scottish forces actively promote the health and welfare of all staff by providing a range of services including CISD and the Employee WellBeing Programme.

Within most Scottish forces, CISD is entirely voluntary. Line managers and supervisors with a duty of care to the welfare of their staff should offer CISD to officers involved in any major or operationally challenging incidents and incidents of a distressing nature. Officers can be referred by line managers or can self-refer by contacting occupational health units for one-to-one counselling. Such services have been relatively underused. Police officers often perceive the admission of experiencing stress or not coping with distressing incidents as being considered as a sign of weakness by their colleagues, which may leave them with a stigma or which may adversely impact on their vocation, affecting their chances of future promotion or likelihood of being accepted into a department. On conducting a study with 450 human resources professionals from the business community, Cubiks found that "susceptibility to stress is very much considered to be a weakness that employees cannot afford to highlight without fear of repercussions" [54]. Such repercussions included $76 \%$ of participants reporting that complaining of stress would damage their career prospects. Seventynine percent of managers confirmed that they would be less likely to promote an employee if they had difficulties handling stress. As a result, confidential counselling or advice is now offered by the Employee Well-Being Programme and officers can phone and speak to an independent nonpolice employee.

Ormerod asserts that debriefing has generally been viewed positively by its recipients and this has led to anecdotal reports of its effectiveness [55]. However, there has been little empirical evidence to demonstrate the effectiveness of psychological CISD in the acceleration of the normal recovery processes following trauma counselling [56, 57]. Experimental designs have not been used to assess the efficacy of CISD [53].

\section{CONCLUSION}

There are numerous studies in the clinical literature, evidencing the exposure to "client" trauma, the association with PTSD-related symptoms and the acknowledgement that STS affects psychological counsellors and other professional groups, emergency services and military combat situations. However, there remains a paucity of research exploring 
the effects of STS on police personnel who investigate cases of child abuse/child protection. Because of the legal obligation of organisations (including police forces) to provide and ensure safe working environment (Health and Safety Act 1974 and Health and Safety at Work Regulations 1999), it is increasingly recognised that employers are responsible for the psychological and physical well-being of their employees in addition to the physical environment in which they work. Force standard operating procedures affirm that it is a responsibility of all managers and supervisors to demonstrate their commitment to health and safety through their actions in support of force policy.

The implications for forces who fail to provide safe working environment for its staff and make available appropriate counselling and training on STS as an effective tool in the management of stress, could be considerable. There is evidence that the harmful effects of stress may negatively impact on officers' resilience and manifest themselves in maladaptive coping mechanisms and/or lead to health complications (both physical and psychological) resulting in an increase in staff absence. The possible negative impact on how effective officers are should not be overlooked, with officers potentially falling short in their service provision to those affected by crime. Poor work performance and job dissatisfaction may lead to reduced motivation, impaired ability to perform complex tasks and potentially reduced standards of investigations and submission of cases. Work-related stress has the potential to lead to an increase in complaints about the police. Ultimately, the lack of police forces' acknowledgement of such phenomena may impact on the personnel resources of the organisation, the personal effectiveness of officers to do their job and potentially lead to an increase in chief officers being the subject of psychological injury claims.

At present the stalemate remains with British Court's rejection and unwillingness to recognise the accumulative effects of STS on police officers who have not been the primary witness/ victim or a close family relative of the person experiencing a traumatic event. However, by police forces being prepared to acknowledge the growing empirical evidence on STS and the potential effects on its child protection officers, this could be a conduit to inform future practice, on the basis of which reasonable precautions, risk assessments, supervisory monitoring and support could be established, with future research on the phenomenon in a police environment, making recommendations as to which appropriate interventions could be made available to meet the needs of staff.

The absence of research on police child protection units highlights a crucial need for research in this occupational group. However, the evidence from published studies should be considered. This could form the foundation on which to inform future police child protection education and learning, supervisory support, practices and policy where necessary, and the provision of appropriate organisation support services. Finally, further empirical studies are required, both from a national and international perspective, on the effects of STS on police officers who conduct child protection enquiries.

\section{REFERENCES}

1. Violanti J, Gehrke A. Police trauma encounters, precursors of compassion fatigue. Int J Emerg Ment Health. 2004;6(2): 75-80.

2. Duckworth D. Facilitating recovery from disaster-work experiences. Br J Guid Counc. 1991;19(1):13-22.

3. Cardwell M. Complete A-Z psychology handbook. London, UK: Hodder \& Stoughton; 2003.

4. Collins paperback English dictionary. 2nd ed. Wrotham, UK: Harper Collins; 1994.

5. Mitchell T, Resnick T. Emergency response to a crisis intervention guide P.O.S.T. for emergency service personnel. Bowie, MD, USA: Robert J. Brady; 1981.

6. Wilson J, Raphael B, editors. International handbook of traumatic stress syndromes. New York, NY, USA: Plenum; 1993.

7. Figley C. Compassion fatigue: toward a new understanding of the costs of caring. 
In: Stamm BH, editor. Secondary traumatic stress: self-care issues for clinicians, researchers and educators. 2nd ed. Lutherville, MD, USA: Sidran Press; 1999. p. 3-38.

8. Breslau N, Davis G, Peterson E, Schultz L. Psychiatric sequelae of posttraumatic stress disorder in women. Arch Gen Psychiatry. 1997;54:81-7.

9. Kessler R, Sonnega A, Bromet E, Nelson C. Posttraumatic stress disorder in the National Comorbidity Study. Arch Gen Psychiatry. 1995:52:1048-60.

10. Stein M, Walker J, Hazen A, Forde A, Ready D. Full and partial posttraumatic stress disorder: findings from a community survey. Am J Psychiatry. 1997;154:1114-9.

11. Chrestman K. Secondary exposure to trauma and self-reporting distress among therapists. In: Stamm BH, editor. Secondary traumatic stress: self-care issues for clinicians, researchers and educators. Lutherville, MD, USA: Sidran Press; 1995. p. 29-36

12. Bride B, Jones J, MacMaster S. Corrolates of secondary traumatic stress in child protective services workers. J Evid Based Soc Work. 2007;4(3-4):69-80.

13. Helm HM. Managing vicarious trauma and compassion fatigue. Retrieved September 20, 2011, from: http://www.lianalo wenstein.com/artcile_helm.pdf

14. Herman J. Trauma and recovery. New York, NY, USA: Basic Books; 1992.

15. McCann I, Pearlman L. Vicarious traumatisation: a framework for understanding the psychological effects of working with victims. J Trauma Stress. 1990;3(2):131-49.

16. Figley C. Compassion fatigue: coping with secondary traumatic stress disorder in those who treat the traumatised. New York, NY, USA: Brunner/Mazel; 1995.

17. Figley C. Compassion fatigue as secondary traumatic stress disorder: an overview. In: Figley CR, editor. Compassion fatigue: coping with secondary traumatic stress disorder in those who treat the traumatised. New York, NY, USA: Brunner/Mazel; 1995. p. 51-81.

18. Kassam-Adams N. The risks of treating sexual trauma: stress and secondary trauma in psychotherapists. In: Stamm BH, editor. Secondary traumatic stress: self-care issues for clinicians, researchers and educators. 2nd ed. Lutherville, MD, USA: Sidran Press; 1999. p. 37-50.

19. Dane B. Child welfare workers: an innovative approach for interacting with secondary trauma. J Soc Work Educ. 2000; 36(1):27-38.

20. Bonifacio P. The psychological effects of police work: a psychodynamic approach. New York, NY, USA: Plenum Press; 1991.

21. Heiman MF. Police suicide. Journal of Police Science Administration. 1975;3: 267-73.

22. Kroes W. Society's victim: the police officer. Springfield, IL, USA: Charles C. Thomas; 1986.

23. Violanti M, Aron, F. Ranking police stressors. Psychol Rep. 1994;75:824-6.

24. Anson, R, Bloom M. Police stress in organizational context. Journal of Police Science and Administration. 1988;16(12): 229-35.

25. Wearing P, Headley B. Police stress and wellbeing: integrating personality, coping and daily work experiences. J Occup Organ Psychol. 1995;68:133-56.

26. Speilberger C, Westbery L, Grier K, Greenfield G. The police stress survey: sources of stress in law enforcement. Tampa, FL, USA: Human Resources Institute; 1981.

27. Sewell J. The development of a critical life events scale for law enforcement. Journal of Police Science and Administration. 1983; 11:109-16.

28. Coman, G, Evans B. Stressors facing Australian Police in the 1990s. Police Studies. 1991;14:153-65.

29. Patterson G. Reconceptualizing traumatic incidents experienced by law enforcement personnel. Australasian Journal of Disaster and Trauma Studies. 2001;(2). Retrieved October 6, 2010, from: http://www.massey .ac.nz/ trauma/issues/2001-2/patterson1.htm

30. Mitchell M, Stevenson K, Poole D. Managing post incident reactions in the police service (HSE Contract Research Report 290/2000). Sudbury, Suffolk, UK: HSE Books; 2000. Retrieved October 6, 2010, from: http://www.hse.gov.uk/resear ch/crr_pdf/2000/crr00290.pdf 
31. Stratton G, Parker A, Snibble R. Posttraumatic stress: study of police officers involved in shootings. Psychol Rep. 1984; 55:127-31.

32. Violanti JM. Trauma stress and police work. In: Paton D, Violanti JM, editors. Traumatic stress in critical occupations: recognition, consequences and treatment. Springfield, IL, USA: Charles C. Thomas; 1996. p. 87-107.

33. Stephens C, Long N, Miller I. The impact of trauma and social support on posttraumatic stress disorder in New Zealand Police officers. J Crim Justice. 1997;25: 303-14.

34. Moran C, Britton NR. Emergency work experience and reactions to traumatic incidents. J Trauma Stress. 1994;7:575-85.

35. Pearlman L, Saakvitne K. Trauma and the therapist: counter-transference and vicarious traumatisation in psychotherapy with incest survivors. New York, NY, USA: Norton; 1995.

36. Buchanan G, Stephens C, Long N. Traumatic experiences of new recruits and serving police. Australasian Journal of Disaster and Trauma Studies. 2001;(2). Retrieved September 20, 2011, from: http://www.massey.ac.nz/\%7Etrauma/ issues/2001-2/buchanan.htm

37. Norris H. Screening for traumatic stress: a scale for use in the general population. $\mathrm{J}$ Appl Soc Psychol. 1992;20:408-18.

38. Martin C, McKean H, Veltkamp L. Posttraumatic stress disorder in police working with victims. A pilot study. Journal of Police Science and Administration. 1986; 14:98-101.

39. Follette V, Polunsy M, Milbeck K. Mental health and law enforcement professionals: trauma history, psychological symptoms, and impact on providing services to child sexual abuse survivors. Prof Psychol Res Pr. 1994;25:275-82.

40. Wright R, Powell M, Ridge D. Child abuse investigation: an in-depth analysis of how police officers perceive and cope with daily work challenges. Policing: An International Journal of Police Strategies and Management. 2006;29(3):498-512.
41. Cornille TA, Woodard Meyers $T$. Secondary traumatic stress amongst child protection service workers: prevalence, severity and predictive factors. Traumatology. 1999;5(1):15-31.

42. Bride B. Prevalence of secondary traumatic stress amongst social workers. Soc Work. 2007;52(1):63-70.

43. Alexander D, Walker L, Innes G, Irving B. Police stress at work. London, UK: The Police Foundation; 1993.

44. Gallo G. Police domestic violence. Police: The Law Enforcement Magazine. 2005. Retrieved September 20, 2011, from: http:// www.policemag.com/Channel/Patrol/ Articles/2005/02/Police-Domestic-Violence -Job-related-stress-is-the-root-of-dysfunctio nal-behavior-in-cops.aspx

45. Health and Safety Executive. Frequently asked questions. Retrieved September 20, 2011, from: http://www.hse.gov.uk/stress/ faqs.htm

46. MacKay CJ, Cousins R, Kelly PJ, Lee S, McCaig RH. "Management standards" and work-related stress in the UK: policy background and science. Work Stress. 2004;18(2):91-112. Retrieved September 20, 2011, from http://www.hse.gov.uk/ stress/techpart1.pdf

47. Scottish Law Commission. Discussion paper on damages for psychiatric injury. 2002. Retrieved September 20, 2011, from: http://www.scotlawcom.gov.uk/download_ file/view/129/

48. Gilligan C. What was it all for? spiked. November 9, 2005. Retrieved March 18, 2010, from: http://www.spiked-online.com/ index.php/site/article/628/

49. Police officers seek trauma compensation. BBC News (7 November 2005). Retrieved September 28, 2011, from http://news.bbc .co.uk/1/hi/northern_ireland/4413762.stm

50. Torres S, Maggard DL, To C. Preparing families for the hazards of police work. The Police Chief. 2003;70(10). Retrieved October 6, 2010, from: http:// policechiefmagazine.org/magazine/index .cfm?fuseaction $=$ display $\&$ article_id $=120$ \&issue_id=102003

51. McFarlane AC, Bryant RA. Posttraumatic stress disorder in occupational 
settings: anticipating and managing risk. Occup Med (Lond). 2007;57(6):404-10. Retrieved September 20, 2011, from: http:// occmed.oxfordjournals.org/cgi/content/ abstract/57/6/404

52. ACPOS Personnel \& Training Standing Committee. Critical incident stress management policy. Report prepared for ACPOS Organisational Health and Welfare Safety Sub-Committee: Critical Incident Stress Management Policy. 2009. Retrieved September 20, 2011, from: http://www .acpos.police.uk/Documents/Policies/P\&T_ CISM_Policy_June09.pdf

53. Mitchell JT, Everly GS. Critical incident stress debriefing (CISD) and the prevention of work-related traumatic stress among high risk occupational groups. In Everly GS, Lating JM, editors. Psychotraumatology. New York, NY, USA: Plenum; 1995. p. 267-280.
54. Cubiks. Hot under the collar: how stress is impacting on the 21 st century business environment. Retrieved September 20, 2011, from: http://www.cubiks.com/Infor mationCentre/ResearchStudies/Pages/collar .aspx

55. Ormerod J. Current research into the effectiveness of debriefing. In: Psychological debriefing: professional practice board working party. Leicester, UK: The British Psychological Society; 2002. p. 8-17. Retrieved September 21, 2011, from: http://intraspec.ca/ PsychologicalDebriefing.pdf

56. Kenardy J. The current state of psychological debriefing. British Medical Journal. 2000;321:1032-3.

57. Rose S. Evidence based practice will affect the way we work. Counselling. BAC Journal. 2000;12(2):105-7. 